American Journal of Immunology 7 (3): 39-53, 2011

ISSN 1553-619X

(C) 2011 Science Publications

\title{
Monoclonal Antibody-Based Therapeutics for Melioidosis and Glanders
}

\author{
${ }^{1}$ Hyung-Yong Kim, ${ }^{1,2}$ Alexander Stojadinovic, \\ ${ }^{3}$ Peter J. Weina, ${ }^{1}$ Ho San Kim, ${ }^{4}$ Shyh-Ching Lo and ${ }^{1}$ Mina J. Izadjoo \\ ${ }^{1}$ Diagnostics and Translational Research Center, \\ Henry M. Jackson Foundation, Gaithersburg, MD 20879, USA \\ ${ }^{2}$ Department of Surgery, \\ Walter Reed National Military Medical Center, Bethesda, MD 20889, USA \\ ${ }^{3}$ Walter Reed Army Institute of Research, Silver Spring, MD 20910, USA \\ ${ }^{4}$ Center for Biologics Evaluation and Research, \\ Food and Drug Administration, Bethesda, MD 20892, USA
}

\begin{abstract}
Problem statement: Burkholderia pseudomallei (BP) and B. mallei (BM) were two closely related pathogenic gram-negative bacteria. They were the causative agents of melioidosis and glanders, respectively and are recognized by $\mathrm{CDC}$ as category B select agents. Significant efforts had been devoted to developing the diagnostic and therapeutic measures against these two pathogens. Monoclonal antibody-based therapeutic was a promising targeted therapy to fight against melioidosis and glanders. Valuable findings have been reported by different groups in their attempt to identify vaccine targets against these two pathogens. Approach: Our group has generated neutralizing Monoclonal Antibodies (MAbs) against BP and BM and characterized them by both in vitro and in vivo experiments. We present an overview of the MAb-based therapeutic approaches against BP and $\mathrm{BM}$ and demonstrate some of our efforts for developing chimeric and fully human MAbs using antibody engineering. Results: Throughout conventional mouse hybridoma technique and antibody engineering (chimerization and in vitro antibody library techniques), we generated 10 chimeric MAbs (3 stable MAbs and 7 transient MAbs) and one fully human MAb against BP and BM. In addition, we present the reactive antigen profiles of these MAbs. Our approaches had potentials to accelerate the development of therapeutics for melioidosis and glanders in humans. Conclusion: Our experience and findings presented here will be valuable for choosing the best antigenic targets and ultimately for the production of effective vaccines for these two pathogens.
\end{abstract}

Key words: Melioidosis, glanders, Burkholderia pseudomallei, B. mallei, monoclonal antibody engineering

\section{INTRODUCTION}

Melioidosis and glanders are caused by the closely related species Burkholderia pseudomallei (BP) and Burkholderia mallei (BM), respectively. BP is a gramnegative, facultative anaerobic, motile bacillus commonly found in the soil and stagnant waters (Leelarasamee, 2004). BP is endemic to Southeast Asia and northern Australia, where melioidosis is an ongoing public health problem (Cheng and Currie, 2005; Mukhopadhya et al., 2007). BP infection is often due to either direct inoculation into wounds and skin abrasions or inhalation of contaminated materials (Chaowagul et al., 1989; Leelarasamee and Bovornkitti, 1989). The clinical manifestation ranges from subclinical to acute and chronic forms (Cheng and Currie, 2005). Symptoms include pain (chest, bones and joints), cough, skin infections, lung nodules and pneumonia. Depending on whether the disease is acute or chronic, melioidosis can mimic other infections, including glanders, typhoid fever, malaria, tuberculosis and bacterial sepsis (Chaowagul et al., 1993; Koponen et al., 1991). The overall mortality rate in individuals infected with BP is $50 \%$ in northeast Thailand $(35 \%$ in children) and 19\% in Australia (Wiersinga et al., 2006). Although melioidosis is primarily found in Southeast Asia and Australia, worldwide spreading evidence has been reported (Currie et al., 2008). Moreover,

Corresponding Author: Mina J. Izadjoo, Diagnostics and Translational Research Center, Henry M. Jackson Foundation, Gaithersburg, MD 20879, USA., Tel: 240-833-4971 Fax: 240-833-4940 
numerous studies revealed that BP could be intrinsically resistant to many antibiotics. Despite therapeutic regimens with certain antibiotics, the mortality rate of melioidosis remains very high (White, 2003). BP infection appears to be consistent with the reported cases of melioidosis occurring in previously healthy US helicopter crews during the Vietnam War, possibly as a consequence of the inhalation of contaminated dusts or mist (Howe et al., 1971). Healthy individuals can develop melioidosis but the majority cases have some underlying immunosuppressive condition, particularly diabetes but also chronic renal disease, thalassemia or alcoholism (Ip et al., 1995). In naturally occurring melioidosis, the mortality rate in acute cases can exceed $50 \%$ and prolonged treatment with antibiotics may result in only temporary control of the infection, with $10-15 \%$ of patients relapsing when antibiotic therapy is withdrawn. The treatment of melioidosis is often problematic because the bacteria are inherently resistant to many of the commercially available antibiotics and successful therapy often requires extended treatment regimens.

Glanders is generally confined to equines in parts of the Middle East, Asia and South America (Reckseidler et al., 2001). BM is a host-adapted pathogen that does not normally persist in nature. In humans, it is primarily an occupational disease, affecting individuals in close contact with infected animals such as veterinarians, grooms and farmers. However, a number of laboratory-acquired cases of glanders have also been reported. BM infection primarily results from the contamination of wounds, abrasions or breaks in mucous membranes. Some studies indicated that BM is highly infectious in humans by aerosol route (Howe et al., 1971). In horses and humans, BM infection can present as either nasalpulmonary infections or cutaneous infections and the disease may develop either acutely or chronically (Whitlock et al., 2007).

There are considerable potentials for these 2 pathogens to be used as Biological Warfare Agents (BWA) (Wiersinga et al., 2006). It has reported that BM was used to attack military horses during World War I and there is direct evidence that BM was also used in World War II and during the Soviet invasion and occupation of Afghanistan (Fong and Alibek, 2005). No effective methods of prevention of either melioidosis or glanders caused by BP and BM currently exist. Studies revealed that BP could be intrinsically resistant to many antibiotics. Development of specific MAbs against these 2 pathogens could provide an important countermeasure in prevention and treatment of the endemic infectious melioidosis and glanders. Unlike vaccines, antibodies can confer passive protection regardless of the immune status of the infected host. In comparison with antimicrobial therapy, $\mathrm{MAb}$ therapy against $\mathrm{BP}$ and $\mathrm{BM}$ infection is significantly promising due to high specific function and low toxicity (Casadevall, 2002). Currently, specific antibodies that protect against infections of highly pathogenic BP and BM that military or civilian populations may encounter in biological warfares have not been developed. There has been a rising interest in these 2 pathogens, mainly not only focusing on their characterization but also identifying vaccine targets (Bondi and Goldberg, 2008; Estes et al., 2010).

Progress of genome sequencing of BP and BM has provided new insights into a better understanding of the pathogenicity, their survival mechanism(s) in the host cell's environment, their potential virulence factors and vaccine candidates (Felgner et al., 2009; Hara et al., 2009; Jones et al., 1996). The survival within host cells and the results of the various vaccine regimens against BP and/or BM (Bondi and Goldberg, 2008; Whitlock et al., 2007) suggests that a cell-mediated immune response, in addition to a humoral response, will be necessary for complete protection from $\mathrm{BP}$ and $\mathrm{BM}$ infection. The similarity of genomes (DNA-DNA homology and base sequence of the $16 \mathrm{~S}$ rRNA) and phenotypic characteristics of these 2 pathogens (Anuntagool and Sirisinha, 2002; Rogul et al., 1970) suggests that vaccines developed against one of these bacteria may be suitable for clearance of the other (Groot and Rappuoli, 2004).

In response to national need for developing countermeasures against biological warfare agents, we have initiated studies on rapid diagnosis, therapeutic MAb development and multi-agent vaccines against BP and BM. To develop high-performance MAbs specific to $\mathrm{BP}$ and $\mathrm{BM}$ as potential therapeutics we used 2 different approaches based on principles using mouse hybridoma production technique and phage-displayed single chain antibody ( $\mathrm{scFv}$ ) technique. The lead MAbs with good neutralizing activity against BP and BM were converted to chimeric and humanized format which can be used to prevent and treat diseases of melioidosis and glanders in humans without having severe side effects. Due to close genetic and antigenic homology among many BP and BM species have made isolation of highly species-specific MAbs very difficult (Anuntagool and Sirisinha, 2002; Cravitz and Miller, 1950). However, good neutralizing MAbs that crossreact to both $\mathrm{BP}$ and $\mathrm{BM}$ could be extremely effective for the therapeutic purpose. Using many different isolates or strains of BP and BM from different geographic regions in the world, generation of MAbs is highly challenging. Since MAb therapy can provide immediate immunity against BP and BM, an overview 
of current technologies for fast-performance production of neutralizing MAbs would be useful for successful development of MAb-based therapies for melioidosis and glanders.

In this review article we discuss our progress during the past over 5 years for therapeutic MAb technology that has proved to be one of modern biology's most sophisticated tools for both basic research and clinical therapies against a wide spectrum of human diseases. There are advantage and disadvantage in development of ideal therapeutic MAbs. Human or humanized MAbs have long half-life, low toxicities and high specificity-much less likely to select for resistance of non-targeted organisms. Since human MAbs are important immune modulators, actions of human antibody may or may not rely on other host mediators. Therefore, it could reduce the damage that results from host inflammatory responses and provide synergistic effects in treatment efficacy against infections when combined with conventional antimicrobial therapy, especially in immune compromised patients. Treatments require knowledge of the causative microbial agents which in turn requires rapid microbiological diagnosis. The objectives of this review are to better understand the passive immunity and MAb-based therapy against Burkholderia infections and to be familiar with the history of MAb development and use in treatment against melioidosis and glanders in human. In addition, we are to be familiar with the pathogenesis associated with 2 pathogenic Burkholderia infections and the development of high-performance MAbs against 2 pathogens using antibody engineering. However, manufacturing and economic hurdles may continue to limit the development of therapeutic MAbs against BP and BM. Ultimately, protective antibodies can provide immediate immunity against $\mathrm{BP}$ and $\mathrm{BM}$ and an important stimulus for the development of MAb-based therapy for melioidosis and glanders.

Technological progresses in MAb production systems: Kohler and Milstein (1975) discovered a method to produce hybridomas and MAbs by immortalizing antibody-producing B cells in culture. For the first time, it was possible to produce in vitro very large quantities of an immunoglobulin of a defined specificity and a single isotype. Since MAb is produced by a single clone of cells having a single binding specificity for an antigenic determinant, the end results after long and laborious processes constitute biological research tools, molecular biology and immunology for the diagnostic testing, purifying substances, targeting specific cell types and many other uses which can be discovered in the future. Hybridoma technology has been rapidly exploited and developed for making humanized MAbs for (pre)clinical use (especially in the fields that effective therapies are urgently needed) (Vaswani and Hamilton, 1998; Weiner et al., 2010). Many new detail methods (Fig. 1) for therapeutic use have been developed for making human hybridomas (Fig. 2) (Li et al., 2006; Karpas et al., 2001; Traggiai et al., 2004; Vaisbourd et al., 2001), human MAbs via transgenic mice (Fishwild et al., 1996; Jakobovits, 1995; Kuroiwa et al., 2009; Lonberg, 2005; 2008; Lonberg and Huszar 1995) and recombinant human MAbs from phage-displayed fragments (Gao et al., 2002; Huls et al., 1999; Irving et al., 1996; Low et al., 1996; Thie et al., 2008; 2011; Zou et al., 2007). Phage displayed MAb has proved much less successful because the phages are sticky and because a small number of specificities quickly come to dominate in the phage population. Therefore, humanization of mouse MAbs via antibody engineering, are still a good approach to analyze complex surface antigens of target infectious agents. Current marketing status of therapeutic MAbs approved by U. S. Food and Drug Administration is summarized (Table 1).

A platform technology for ideal therapeutic MAbs should constitute the most complete technology solution available in the marketplace for generating fully human antibodies and enables us to produce antibodies that meet the industry standard in that they are (1) $100 \%$ human, (2) of a very high affinity and (3) can be produced and manufactured relatively quickly and efficiently (Dübel, 2004; Reichert, 2002). Current human antibody technologies offer the following advantages over other conventional antibody technologies. Fully human antibody development system, unlike humanization techniques, can be generated antibodies with $100 \%$ human protein sequences, which permit the development of end products with a favorable safety profile. Additionally, fully human MAbs are likely to be eliminated less rapidly from the human body, potentially reducing the frequency and amount of dosing. Human antibodies having high affinity to target antigen take advantage of the human body's natural affinity maturation process (whereby antibodies evolve over time to have higher affinity to targets) (Vaughan et al., 1998). Since high affinity antibodies have been generated against a wide range of target antigens, these MAbs are produced without the need for any subsequent engineering to make them more human-a process that at times has proven to be challenging and time consuming. Rapid development capabilities of fully human antibodies can accelerate the progress from immunization to the clinic. 
Am. J. Immunol., 7 (3): 39-53, 2011

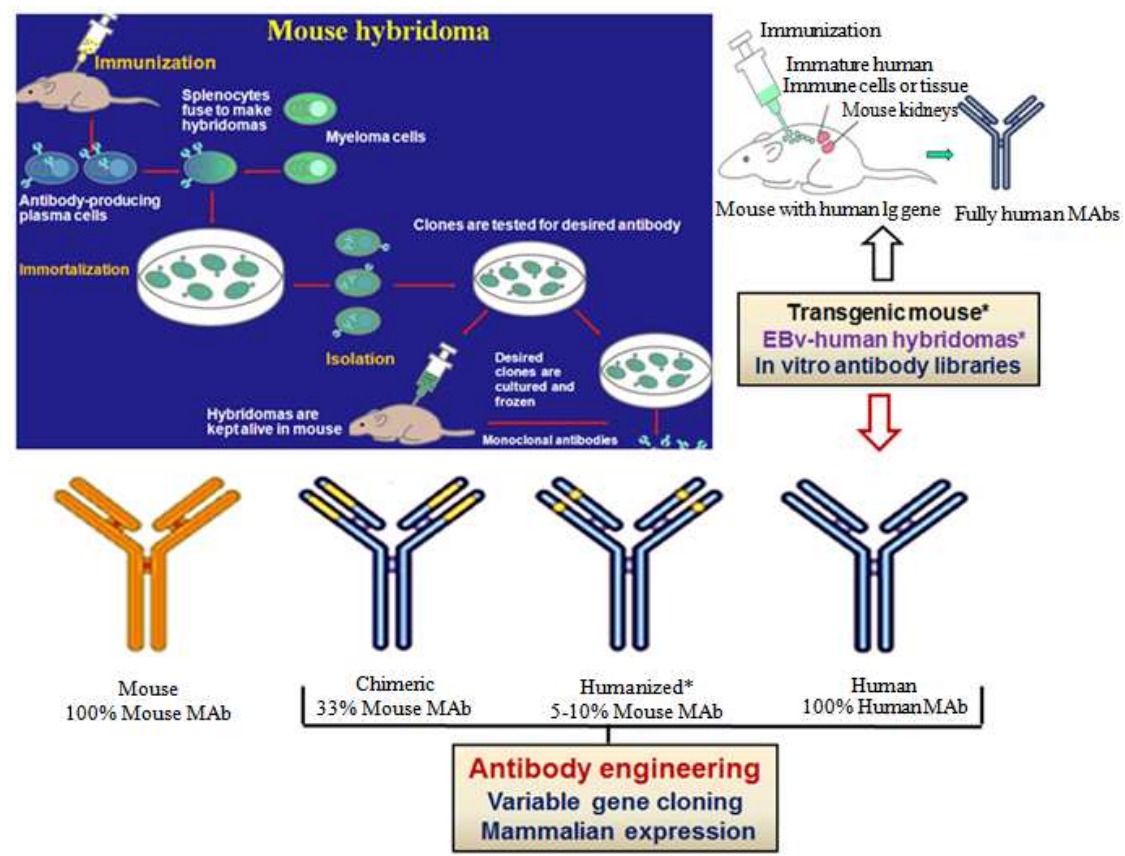

Fig. 1: Progress of current technologies for production of monoclonal antibody. Throughout the mouse hybridoma technique and antibody engineering (chimerization and in vitro antibody library techniques), we generated 10 chimeric MAbs (3 stable MAbs and one fully human MAb against BP and BM. *Other techniques [transgenic mouse, Epstein-Barr virus (EBv)-hybridoma and humanization via CDR-grafts] are also promising to make efficient human (ized) MAbs

\section{Development of fully human MAbs against targeted agents}

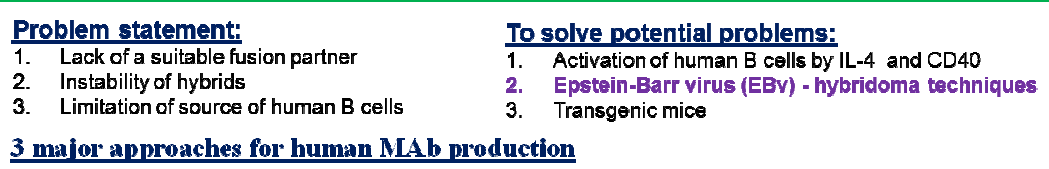

\begin{tabular}{|c|c|c|c|}
\hline & Hylyddoma tecluniques & EBv fmmortalization techuique & EBv-hybridoma technique \\
\hline Advantages & Fuston emclency is high & $\begin{array}{l}\text { Epstefn-Barr vins is the only } \\
\text { vins known to iminortalize } \\
\text { human B byphocytes. }\end{array}$ & $\begin{array}{l}\text { PEG-reststant/ HAT sensittve } \\
\text { human inyeloma cell line, Karpas } \\
707 \mathrm{~T} \text { is available. }\end{array}$ \\
\hline Dikadrantages & $\begin{array}{l}\text { 1. Lost human chromosome } \\
\text { 2. Last Ah production }\end{array}$ & 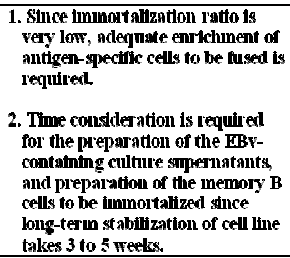 & $\begin{array}{l}\text { Ethical condderntion due to } \mathrm{Al} \\
\text { production by human cancer cell } \\
\text { line }\end{array}$ \\
\hline $\begin{array}{l}\text { Maximum } \\
\text { Secretion }(\mu \mathrm{g} / \mathrm{m}) \text { ) }\end{array}$ & $3-11$ & 0.1-16 & $\sim 200$ \\
\hline Current Status & Successfol & Snccessful & Fromising \\
\hline
\end{tabular}

Fig. 2: Human hybridoma technology. Three major approaches have been developed to produce fully human MAbs. For a small-scale production, the conventional human hybridoma technique can be used by direct fusion of memory B cells with human myeloma cells. The EBv-transfected hybridoma technology via human Karpas $707 \mathrm{H}$ myeloma cells as a fusion partner is also promising for successful development of fully human MAbs, in terms of production levels, purification and application in the downstream 
Am. J. Immunol., 7 (3): 39-53, 2011

Table 1: Current marketing status of therapeutic MAbs approved by the U.S. Food and Drug Administration

\begin{tabular}{|c|c|c|c|c|c|}
\hline $\begin{array}{l}\text { Therapeutic MAbs } \\
\text { Type }\end{array}$ & Product & Target & Therapeutics & Marketer & $\begin{array}{l}\text { Current, } 2011 \\
\text { Approved }\end{array}$ \\
\hline Murine & OKT3 & CD3 & $\begin{array}{l}\text { Allograph } \\
\text { rejection }\end{array}$ & $\begin{array}{l}\text { Johnson and } \\
\text { Johnson }\end{array}$ & June, 1986 \\
\hline $\begin{array}{l}\text { Murine- } \\
\text { Radiolabeled }\end{array}$ & Zevalin & $\mathrm{CD} 20$ & $\begin{array}{l}\text { Non-Hodgkin's } \\
\text { lymphoma }\end{array}$ & $\begin{array}{l}\text { IDEC Pharmaceuticals } \\
\text { and Schering AG }\end{array}$ & March, 2002 \\
\hline $\begin{array}{l}\text { Murine- } \\
\text { Radiolabeled }\end{array}$ & Bexxar & CD20 & $\begin{array}{l}\text { CD20+ Follicular, } \\
\text { Non-Hodgkin's } \\
\text { lymphoma }\end{array}$ & $\begin{array}{l}\text { Corixa Corp. and } \\
\text { GlaxoSmithKline }\end{array}$ & June, 2003 \\
\hline Chimeric & ReoPro & GPIIb, IIIa & PTCA adjunct & $\begin{array}{l}\text { Centocor (Johnson and } \\
\text { Johnson) and Eli Lilly }\end{array}$ & December, 1994 \\
\hline Chimeric & Rituxan & CD20 & $\begin{array}{l}\text { Non-Hodgkin's } \\
\text { lymphoma }\end{array}$ & $\begin{array}{l}\text { Biogen-Idec and } \\
\text { Genenech }\end{array}$ & November, 1997 \\
\hline Chimeric & Simulect & CD25 & $\begin{array}{l}\text { Organ rejection } \\
\text { prophylaxis }\end{array}$ & Novartis & May, 1998 \\
\hline Chimeric & Remicade & TNF- $\alpha$ & $\begin{array}{l}\text { Rheumatoid arthritis, } \\
\text { Crohn's disease }\end{array}$ & $\begin{array}{l}\text { Centocor (Johnson } \\
\text { and Johnson) }\end{array}$ & August, 1998 \\
\hline Chimeric & Erbitux & EGFR & Colorectal cancer & $\begin{array}{l}\text { ImClone Systems and } \\
\text { Bristol Myers Squibb }\end{array}$ & February, 2004 \\
\hline Humanized & Zenapax & $\mathrm{CD} 25$ & $\begin{array}{l}\text { Organ rejection } \\
\text { prophylaxis }\end{array}$ & $\begin{array}{l}\text { Roche and Protein } \\
\text { Design Labs }\end{array}$ & December, 1997 \\
\hline Humanized* & Synagis & RSV-F protein & $\begin{array}{l}\text { Respiratory syncytial } \\
\text { virus (RSV) disease }\end{array}$ & Medimmune & June, 1998 \\
\hline Humanized & Herceptin & HER-2 & $\begin{array}{l}\text { Metastatic breast } \\
\text { cancer }\end{array}$ & Genentech & September, 1998 \\
\hline Humanized & Campath & CD52 & $\begin{array}{l}\text { Chronic lymphocytic } \\
\text { leukemia }\end{array}$ & $\begin{array}{l}\text { Millennium Pharma } \\
\text { ceuticals and Berlex Lab }\end{array}$ & July, 2001 \\
\hline Humanized & Xolair & IgE & $\begin{array}{l}\text { Moderate to severe } \\
\text { persistent asthma }\end{array}$ & $\begin{array}{l}\text { Genentech, Tanox, } \\
\text { and Novartis }\end{array}$ & June, 2003 \\
\hline Humanized & Avastin & VEGF & $\begin{array}{l}\text { Metastatic colorectal / } \\
\text { breast cancers }\end{array}$ & Genentech & February, 2004 \\
\hline Humanized & Tysabri & $\alpha 4$ subunit & $\begin{array}{l}\text { Multiple sclerosis } \\
\text { and Chron's disease }\end{array}$ & $\begin{array}{l}\text { Biogen-Idec and } \\
\text { Elan Corp. }\end{array}$ & November, 2004 \\
\hline Humanized & Lucentis & VEGF-A & $\begin{array}{l}\text { Wet age-related } \\
\text { macular degeneration }\end{array}$ & Genentech & June, 2006 \\
\hline Humanized & Soliris & Complement C5 & $\begin{array}{l}\text { Paroxysmal nocturnal } \\
\text { hemoglobinuria }\end{array}$ & $\begin{array}{l}\text { Alexion } \\
\text { Pharmaceuticals, Inc }\end{array}$ & March, 2007 \\
\hline Humanized & Cimzia & TNF- $\alpha$ & $\begin{array}{l}\text { Rheumatoid arthritis, } \\
\text { Crohn's disease }\end{array}$ & UCB & April, 2008 \\
\hline Humanized & Actemra & Anti-IL6R & Rheumatoid arthritis & Roche & January, 2010 \\
\hline Phage-displayed & Humira & TNF- $\alpha$ & Rheumatoid arthritis & $\begin{array}{l}\text { Abbott Labs / Cambridge } \\
\text { Antibody Technology }\end{array}$ & December, 2002 \\
\hline Transgenic & Vectibix & EGFR & $\begin{array}{l}\text { Metastatic } \\
\text { colorectal cancer }\end{array}$ & Amgen/Abgenix & September, 2006 \\
\hline Transgenic & Simponi & TNF- $\alpha$ & $\begin{array}{l}\text { Rheumatoid and } \\
\text { psoriatic arthritis }\end{array}$ & $\begin{array}{l}\text { Centocor (Johnson } \\
\text { and Johnson) }\end{array}$ & April, 2009 \\
\hline Fully human & Ilaris & IL-1 $\beta$ & $\begin{array}{l}\text { Cryopyrin-associated } \\
\text { periodic syndromes }\end{array}$ & Novartis & June, 2009 \\
\hline $\begin{array}{l}\text { Transgenic/ } \\
\text { hybridoma }\end{array}$ & Arzerra & CD20 & $\begin{array}{l}\text { Chronic lymphocytic } \\
\text { leukemia }\end{array}$ & $\begin{array}{l}\text { Genmab / } \\
\text { GlaxoSmithKline }\end{array}$ & October, 2009 \\
\hline Fully human & Stelara & IL-12/IL-23 & Plaque psoriasis & Centocor & November, 2009 \\
\hline $\begin{array}{l}\text { Fully human } \\
\text { Transoenic }\end{array}$ & $\begin{array}{l}\text { Prolia } \\
\text { Vervoy }\end{array}$ & $\begin{array}{l}\text { RANKL } \\
\text { CTLA-4 }\end{array}$ & $\begin{array}{l}\text { Postmenopausal osteoporosis } \\
\text { Metastatic melanoma }\end{array}$ & $\begin{array}{l}\text { Amgen } \\
\text { Bristol Mvers Squibb }\end{array}$ & $\begin{array}{l}\text { June, } 2010 \\
\text { March } 2011\end{array}$ \\
\hline
\end{tabular}

In order to diverse selection of antibodies responding to many target antigens, the technology should have a potential to generate high affinity human antibodies of all isotypes and subclasses that recognize more antigen structures. In addition, the technology should have been able to create large panels of MAbs against many potentially relevant antigens.

For a given antigen target, the ability to select a product candidate from a pool of multiple therapeutic MAbs could be imperative in selecting the optimal antibody product for development. Here we present our extensive efforts (mouse MAbs to human MAbs) to generate high-performance therapeutic MAbs against $\mathrm{BP}$ and BM. These MAbs can be useful to study
Burkholderia pathogenicity and to prevent melioidosis and glanders diseases of humans and animals.

Production and characterization of mouse MAbs against BP and BM: To generate hybridomas and MAbs against BP and BM, in our initial attempt we hyper-immunized $\mathrm{BLAB} / \mathrm{c}$ mice with whole cell antigens and Lipid-Associated Membrane Proteins (LAMPs) with Lipopolysaccharides (LPS) from heatkilled BP ATCC 23343 and BM ATCC 23344. Thereafter, to make diverse MAb pools in other immunization attempts, the antigen was prepared as several types such as whole cell antigens of heatinactivated $\left(65^{\circ} \mathrm{C}\right.$ for $\left.90 \mathrm{~min}\right) \mathrm{BP}$ and $\mathrm{BM}$, capsular 
polysaccharides (>200-kDa exo-polysaccharides) on surface of all BP strains and about $50 \%$ of the BM strains and LAMPs/LPS, known to have different epitopes between BP and BM. Throughout three I-steps (immunization, immortalization and isolation) (Fig. 1), the antisera of immunized mice had a titer of approximately $1: 10^{6}$ against the whole bacteria by ELISA and a titer of approximately $1: 10^{5}$ against the capsular and LPS antigen. As expected, polyclonal antisera from mice immunized by whole cell antigens of $\mathrm{BP}$ (or BM) cross-reacted strongly with the whole cell antigens of BP, BM and B. thailandensis (BT) by either ELISA or Western Blotting (WB) (Feng et al., 2006) We identified hybridomas producing BP- and BM-specific MAbs that do not cross-react with other 8 non-pathogenic Burkholderia species $[B$. cepacia (ATCC 700070), B. vietnamiensis (ATCC BAA-248), B. stabilis (ATCC BAA-67), B. ambifaria (ATCC BAA-244), B. caledonica (ATCC BAA-462), $B$. kurureinsis (ATCC 700977), B. multivorans (ATCC BAA-247) and B. fungorum (ATCC BAA-463)]. All $\mathrm{BP}$ and BM-specific MAbs obtained were characterized for their specificity and the nature of bacterial antigens they reacted to [glycoproteins, capsule polysaccharides and LPS] (Zou et al., 2008). We continued our attempt of developing more hybridomas for specific MAbs against $\mathrm{BM}$ by immunizing 2 clinical bacterial isolates (BM005 and BM007) other than the prototype BM ATCC 23344 strain. Similar attempt to MAbs against BP was conducted by immunizing mice with 3 different clinical isolates (BP8324, BP430 and BP428) other than the BP ATCC 23343. All together we generated and characterized 108 individual hybridomas producing MAbs that reacted strongly with BP and/or BM by ELISA (Feng et al., 2006; Zou et al., 2008). Immunoglobulin isotype of each MAbs was also determined. Most MAbs belong to type $\operatorname{IgG}$ or $\operatorname{IgM}$ with a few belonging to type IgA. In addition, we examined binding properties and cross-reactivity of the MAbs to non-Burkholderia species of bacteria or to a closely related species of Pseudomonas aeruginosa using ELISA and WB. MAb affinity ranking to target antigens has been determined by using Biacore's Surface Plasmon Resonance (SPR) biosensor technology (Canziani et al., 2004; Wohlhueter et al., 1994). To ensure the selected MAbs were able to recognize as many different strains or clinical isolates of pathogenic BP and BM, we examined each MAbs for their reactivity to 16 different strains or clinical isolates of BM and 13 different strains or clinical isolates of BP. Anti-BP LPS MAbs often cross-reacted with the BT LPS. We also examined the bactericidal activities of 47 candidate MAbs by in vitro studies. The opsonic assay using dimethyl sulfoxide-treated human HL-60 cells as phagocytes revealed that 19 out of 47 tested MAbs (40\%) have prominent bactericidal activities against BP and/or BM. Then, the in vivo protective efficacy of selected MAbs was evaluated using female 8-10 weekold $\mathrm{BALB} / \mathrm{c}$ mice challenged intranasally with predetermined dose (20xLD50) of the bacteria. Groups of six mice under anaesthetization were intravenously injected with $100 \mu \mathrm{g}$ of purified MAb in $0.4 \mathrm{~mL}^{-1}$ of PBS or control serum. Mice were allowed to rest for $2 \mathrm{~h}$ prior to challenge intranasally with $\mathrm{BP}$ or $\mathrm{BM}$. The mice after challenge were observed daily and mortality rate was recorded over a period of 3 weeks for BP and 2 weeks for BM (Zhang et al., 2011). Mouse protection assay by lead MAbs from our group and other investigators showed that these MAbs reactive to either the capsular polysaccharides or LPS were effective in protecting mice against lethal bacterial challenge challenge (Jones et al., 2002; Trevino et al., 2006; Zhang et al., 2011).

Affinity improvement of neutralizing MAbs: Our lab has successfully developed the high-performance MAbs that can ultimately be used into therapeutic for the prophylaxis and treatment of melioidosis and glanders. The rationale that underlies past 3 year study was that we would improve specific MAbs against BP and BM using approaches based on 2 completely different principles-affinity improvement by single chain antibody ( $\mathrm{scFv}$ ) phage display technique (Irving et al., 1996; Low et al., 1996; Kim et al., 2011a; Thie et al., 2008; 2011) and chimerization of lead MAbs via antibody engineering (Kim et al., 2011b). The traditional mouse hybridomas technique would most likely produce MAbs that recognize bacterial antigens processed by professional antigen-presenting cells in mice. The functional full human IgG format of $\mathrm{scFv}$ MAbs might have the unparalleled advantage in the applicability of antibody therapies to diseases of melioidosis and glanders in humans. Overall, we generated and characterized 108 different mouse MAbs against BP and BM (Feng et al., 2006; Zou et al., 2008). We also studied more than 40 human scFv MAbs obtained by panning of human $\mathrm{scFv}$ phage library against BP and BM and eventually selected 9 scFv MAbs (Zou et al., 2007). The specificity (crossreacting to other Burkholderia species or nonBurkholderia species bacteria) and sensitivity (reacting to other clinical strains or isolates of $\mathrm{BP}$ and $\mathrm{BM}$ ) as well as the nature of bacterial antigens recognized by these MAbs were all carefully studied. We completed the testing of the representative mouse MAbs from each of the 8 different groups of MAbs (Zou et al., 2008) for 
in vitro antibody-mediated bacterial killing assays and bacteria opsonic assays against BP and BM. Furthermore, we have identified 2-3 most effective mouse MAbs of protecting animals against lethal infections of BP and BM, respectively (Zhang et al., 2011).

The neutralizing activity of MAbs is closely related to their antigen binding affinity. Many approaches have been developed to improve antibodies, including random Complementarity-Determining Regions (CDRs) mutagenesis, chain shuffling and error prone PCR (Wark and Hudson, 2006). Among these approaches, random mutagenesis on hotspots in CDRs (Yau et al., 2005), mainly CDR3 is most commonly used and successful (Irving et al., 1996). Therefore, we have first focused on site-directed mutational approach at CDR3. Phage-displayed $\mathrm{scFv}$ antibody technology with scFvs displayed on M13 phage has been well established (Thie et al., 2011; Yau et al., 2005; Zou et al., 2007). We used this system to build mutation scFv libraries for the selected MAbs. An engineered antibody for improving their antigen binding affinity is actually one of the most extensively studied areas of antibody engineering. There are basically two approaches to improve antibody affinity. The first approach was to create very large libraries of randomly mutated CDRs or the entire variable domains and then select for higher affinity variants from this large collection of mutants (Kim et al., 2011a; Wark and Hudson, 2006). The second approach is to make small libraries by focused CDR3 mutagenesis that may increase the likelihood of identifying higher affinity variants. Combinations of different mutations that lead to small increases in affinity often have addictive or synergistic effect and lead to a greater improvement in affinity (Chowdhury and $\mathrm{Wu}, 2005)$.

Construction and panning of phage-displayed scFv libraries containing mutations in CDRs for affinity improvement: To improve antibody binding affinity to target antigens, we used a process targeting random mutations to the hotspots in the variable regions of MAbs (Yau et al., 2005). During somatic hypermutation mutations in genes encoding the antibody variable domains are preferentially focused in certain regions termed "hotspots". The essence of the approach is to mimic in vitro the natural somatic hypermutation process that underlies affinity maturation of antibodies in vivo (Neuberger and Milstein, 1995). The consensus sequence of hotspots is the tetranucleotide, RGYW (in which R can be A or G, $\mathrm{Y}$ can be $\mathrm{C}$ or $\mathrm{T}$ and $\mathrm{W}$ can be $\mathrm{A}$ or $\mathrm{T}$ ). The AGY serine codons may also constitute hotspots (Wark and Hudson, 2006; Yau et al., 2005). The hotspots with value for further mutations generally locate at sites in contact with the antigens. To improve anti-Burkholderia MAb binding affinity, 6 mouse scFvs constructed previously were used to construct large highly-diversified phagedisplayed mouse scFv libraries (Kim et al., 2011a).

Humanization of neutralizing MAbs: Treatments of various infectious diseases normally would require relatively short-term regimens compared with treatments of chronic forms of illnesses such as malignancies or autoimmune diseases (Adams and Weiner, 2005). However, potential human anti-murine immune response as well as subtle adverse effects produced by the foreign mouse antibodies in human is still major concerns in using mouse MAbs as therapeutics against infectious agents. At present, most therapeutic MAbs used in the clinic are either humanized MAbs or fully human MAbs (Table 1). A full format antibody molecule of human, mouse and most other mammalian species consists of a light chain and heavy chain linked together by S-S bonds. Both light and heavy chains contain highly variable $\mathrm{N}$ terminal regions (VL and $\mathrm{VH}$ ) and C-terminal constant regions. The $\mathrm{VL}$ and $\mathrm{VH}$ are critical for antigen specificity and binding affinity. Chimeric mouse-human MAbs generally are composed of VL and VH from the original mouse MAbs fused with the respective human light and heavy chain constant regions. Through molecular manipulation approaches, the highperformance MAbs can ultimately be used to effectively protect human victims against $\mathrm{BP}$ and $\mathrm{BM}$ infections.

\section{Production and characterization of chimeric mouse-} human MAbs against BP and BM: BP and BM as well as many other species in the Burkholderia family show a high homology at the nucleotide level (Rogul et al., 1970) by Basic Local Alignment Search Tool (BLAST) comparisons (Altschul et al., 1997). Serological studies also revealed BP and BM are antigenically closely related (Cravitz and Miller, 1950). Development of ideal therapeutic MAbs that can differentiate between all strains of BP and BM from other non-pathogenic Burkholderia species has been challenging due to the close homology. However, if the MAbs developed were to be used for therapeutic and not diagnostic purposes, MAbs that react strongly to both BP and BM are highly desirable. Furthermore, to design therapeutic MAbs for human diseases, it is important that the selected MAbs react not only to the particular strain of bacteria used as the immunogen, but to as many different strains and clinical isolates of these two closely related species of bacterial pathogens as possible (Brekke and Sandlie, 2003). 
Am. J. Immunol., 7 (3): 39-53, 2011

Table 2: Engineered therapeutic MAbs against BP and BM

\begin{tabular}{|c|c|c|c|c|c|c|}
\hline \multicolumn{3}{|c|}{ Mouse hybridoma } & \multicolumn{2}{|c|}{ Reactive antigen and specificity } & \multicolumn{2}{|c|}{ Conversion and expression } \\
\hline MAb ID & Immunization & Isotype & By WB $^{1}$ & By ELISA $^{2}$ & Chimeric MAb & Human MAb \\
\hline BP7 10B11 & BP430 & $\operatorname{IgG} 1 / \kappa$ & Glycoproteins & BP, BM: +; BT: - & Stable & \\
\hline BM-1 & BM005 & $\operatorname{IgG} 1 / \kappa$ & (Glyco)proteins & BP, BM: + & & Transient \\
\hline BP7 2F4 & BP430 & $\operatorname{IgG} 2 \mathrm{~b} / \kappa$ & Capsular polysaccharides & BP, BM: + ; BM005, BT: - & Transient & \\
\hline BP2 I67 & BP8324 & $\mathrm{IgG} 1 / \kappa$ & Capsular polysaccharides & BP, BM: + ; BM005, BT: - & Transient & \\
\hline BP7 2C6 & BP430 & $\operatorname{IgG} 2 \mathrm{a} / \kappa$ & Capsular polysaccharides & BP, BM: + ; BM005, BT: - & Stable & \\
\hline BP1 2E7 & BP8324 & $\mathrm{IgG} 3 / \kappa$ & Capsular polysaccharides & BP, BM: +; BM005, BT: - & Transient & \\
\hline BP1 7F7 & BP8324 & $\operatorname{IgG} 3 / \kappa$ & LPS & BP, BT: + & Stable & \\
\hline BP A2 & BP ATCC & $\mathrm{IgG} 1 / \kappa$ & LPS & BP, BT: + & Transient & \\
\hline BP L30 & BP ATCC & $\operatorname{IgG} 2 \mathrm{a} / \kappa$ & LPS & BP, BT: + & Transient & \\
\hline BML 5D11 & BM ATCC & $\operatorname{IgG} 2 b / \lambda$ & LPS & BM: +; BP: weakly + & Transient & \\
\hline BML 18F8 & BM ATCC & $\operatorname{IgG} 1 / \lambda$ & LPS & BM: +; BP: weakly + & Transient & \\
\hline
\end{tabular}

${ }^{1}$ The nature of antigenic epitopes recognized by each MAb was characterized by Western blot analysis against heat-killed whole bacterial cell lysates with or without proteinase K-treatment (against protein epitopes), with or without sodium periodate-treatment (against carbohydrate epitopes); ${ }^{2}$ ELISA was done against heat-killed whole bacteria of specified Burkholderia species [B. pseudomallei (BP) ATCC 23344 and $B$. mallei (BM) ATCC 23343] and clinical isolates (13 BPs and 16 BMs). BT indicates B. thailandensis ATCC 70038

In our previous studies, more than 100 mouse MAbs against BP and/or BM have been generated and characterized (Feng et al., 2006; Zou et al., 2008). Most importantly, many of these MAbs showed good protection efficacy against both pathogenic Burkholderia bacteria by an in vitro opsonic assay using HL-60 cells and mouse protection assay via intranasal challenge with a sub-lethal dose of the bacteria (Zhang et al., 2011). However, a recent mouse protection study against BP and/or BM infection has shown that MAbs against capsular polysaccharide, LPS and glycoproteins of BP and/or BM significantly reduce lethality of infections in mice. These MAbs fail to achieve full protection, especially with high dose challenges (Jones et al., 2002; Trevino et al., 2006; Zhang et al., 2011). Development of high-performance MAbs which could be used as therapeutics in exposed individuals is urgently needed to fill the current gap in defense against BWAs. Three major surface antigen [(glyco)proteins, capsular polysaccharides and LPS]reactive MAbs against $\mathrm{BP}$ and/or BM were selected to further develop chimeric MAbs (Kim et al., 2011b). The ultimate goal was to develop superactive MAbs that can be used as therapeutics against BM and BP infections.

Recent advancements in entire genomic sequence information of BP and BM allowed us to identify potential vaccine candidates for melioidosis and glanders (Felgner et al., 2009). Since facultative intracellular BP and BM are capable of residing in host cell compartments, which can be escaped from either antibiotic or vaccines (Jones et al., 1996), it is believed that intracellular survival compartments may be a key element for determination of virulence factors. Therefore, it is likely that a cell-mediated immune response, perhaps in addition to a humoral response, may be critical for protection, as has been shown for other intracellular bacterial pathogens. Recent studies of the role of Burkholderia outer surface antigens in mouse protection by using MAbs post-nasal or lethal challenges of pathogenic Burkholderia species indicate that the Burkholderia surface antigens [Outer Membrane Proteins (OMPs), LPS and capsular polysaccharides] are potential protective antigenic targets (Felgner et al., 2009; Hara et al., 2009; Nelson et al., 2004; Plesa et al., 2004). Our ELISA data and Western blot analysis by 3 chimeric MAbs, using the treated antigens (heat, sodium periodate and proteinase $\mathrm{K}$ ) and OMPs of BP and BM, revealed each chimeric MAb's reactivity to bacterial cell components and immunodominant antigens with different molecular size from 21-65 $\mathrm{kDa}$ (Kim et al., 2011b). Briefly, due to different antigen reactivities (surface glycoproteins, capsular polysaccharide antigens, LPS and/or Lipoproteins (LP) by therapeutic MAbs (Table 2), these MAbs would be useful for neutralizing BP and/or BM infection and studying the role of the major surface antigens in Burkholderia infection. Furthermore, since LP is a major component of the outer membrane of gram-negative bacteria, LP in culture supernatants of growing Burkholderia cells may induce pathologic changes associated with infections (Zhang et al., 1998). Our previous studies of in vitro neutralization and original MAb ranking using Biacore's SPR technique suggest that the surface epitopes (with little crossreactivity to other Burkholderia bacteria) recognized by these MAbs are highly specific to target Burkholderia species. Thus, these cross-reactive antigens in BP and BM may be useful for determining potential vaccine targets against Burkholderia infection.

Humanization of the target MAbs could minimize possible side effects when used as human therapeutics (Chan et al., 2004; Reff et al., 1994). Therefore, the chimerization of these three MAbs against BP and BM is an important step in the preclinical development. The 
utilization of bicistronic retroviral expression vectors containing the gene of interest (Thomas et al., 2003) and an amplifiable marker gene has been shown as an effective method in obtaining stable cell lines that express high levels of the chimeric MAb of interest (Bianchi and McGrew, 2003; Kim et al., 1998; Lucas et al., 1996). However, experience with the use of such vectors in high level expression of chimeric MAbs is currently limited. To obtain sufficient quantities of chimeric MAbs for the preclinical therapeutics, we established a platform technology to develop cell lines producing high levels of neutralizing chimeric MAbs against BP and/or BM. This include (1) construction of four major different mammalian expression vector systems with a Dihydrofolate Reductase (DHFR) amplification marker, (2) optimization of transfection/selection conditions in Chinese Hamster Ovarian (CHO) cells and other common mammalian host cells with the single-gene (heavy or light chain) vectors and double-gene vector (both heavy and light chain in the vector) system, (3) stable chimeric MAb production by CHO-DG44 cells and (4) affinity purification (Kim et al., 2011b). These techniques would be useful for accelerating preclinical development of therapeutic chimeric MAbs against targeted $\mathrm{BP}$ and $\mathrm{BM}$.

Development of human scFvs MAbs by screening phage-displayed naive human scFv libraries against BP and BM: Much effort to make fully human MAbs has been devoted to the development of mouse MAbs that react specifically with $\mathrm{BP}$ and BM for diagnostic and/or therapeutic purposes. Our lab have been focused on the screening of a phage-displayed human $\mathrm{scFv}$ antibody library against heat-killed BP and BM for the generation of human $\mathrm{scFv}$ antibodies specific to the two pathogenic species of bacteria. Three phage-displayed human naïve scFv libraries from different sources have been acquired and propagated from the E. coli stocks (XL1-blue, TG-1 and HB2151). Although we initially tested 3 different phage-displayed human naïve $\mathrm{scFv}$ libraries, we subsequently focused on one particular phage-displayed human naïve $\mathrm{scFv}$ library that had provided most consistent results, for more extensive screenings for scFvs against heat-killed whole cell bacteria as well as SDS lysates (coated on immunesticks) of BP ATCC 23343 and BM ATCC 23344.

Using two different panning procedures against BP and $\mathrm{BM}$, we obtained seven different human $\mathrm{scFv}$ phage antibodies that interacted with the heat-killed whole bacterial cells of BP and BM. Our results demonstrate that panning of a human $\mathrm{scFv}$ antibody library against heat-killed whole bacterial cells may provide a valuable strategy for developing human MAbs against the highly pathogenic BP and BM. We successfully obtained more than 40 clones of human
scFv phage MAbs that reacted with BP and BM. All these selected clones of $\mathrm{scFv}$ phage MAbs were characterized by DNA sequencing and classified into different families. These human $\mathrm{scFv}$ phage libraries were useful for screening against whole cell antigens of heat-killed BP ATCC 23343 and BM ATCC 23344 of interest large stocks of helper phages (VCSM13 and M13 KO7).

To reconstruct of scFv into fully human $\mathrm{IgG} 1$, we constructed recombinant genes of light and heavy chains of full human format IgGs by fusing the VL and VH sequences from each of 4 scFvs (BM1, 3A2, 1F3 and 1D7) with the human light (kappa) and heavy chain (gamma) constant region sequences, respectively. The fusion genes were then cloned in the mammalian expression vector pcDNA3. Expression of one human format IgG1 (BM1) from transiently transfected CHO cells and 293T cells was proved to be successful. The specificity and relative binding activity of transiently expressed human anti-BM1 was tested and found to be the same as that of the original scFv MAb and mouse MAbs (Zou et al., 2007).

Stable MAb production: Cells used for the production of therapeutic MAbs must comply with various requirements to ensure approval for the MAb as a drug (Reichert, 2011). One of those requirements is to use a thoroughly defined clone. It must be guaranteed that the cells used for MAb production are derived from a single clone with a specifically-defined integration site. The generation of a stable clone often requires 6 months or more due to selection procedures and adaptation to serum-free conditions. A variety of systems for selecting transfected cells exists, including resistance to antibiotics such as neomycin, hygromycin and puromycin, Dihydrofolate Reductase (DHFR) (Kim et al., 1998; Lucas et al., 1996) and Glutamine Synthetase (GS) systems (Jun et al., 2006). The aim of selection is to identify high producing clones, but this is tedious and laborious processes. Although several methods for isolating clones are used, the most popular subcloning is used by limiting dilution using multi-well plates or cloning cylinders. Once a stable clone is selected, it must be adapted to serum-free suspension culture so that it can be used in efficient large-scale production This adaptation process is again time consuming and bears the risk that the clone may lose its desired high producing properties. By applying novel transfection technologies, mammalian cells can be transfected directly in a serum-free environment. This saves significant time and reduces the risk on the way to find the right clone.

In our attempt to establish stable cell lines that express the chimeric MAbs against $\mathrm{BP}$ and $\mathrm{BM}$, we introduced the chimeric heavy and light chain genes 
cloned in an expression vector that carries the DHFR or GS amplifiable selection markers, into the DHFRdeficient Chinese Hamster Ovarian cells (CHO-DG44) (Kim et al., 2011b). CHO-DG44 with the expression vector integrated into the chromosomes was selected and the copy numbers of the integrated chimerical heavy and light chain genes was further amplified by selective agents such as Methotrexate (MTX) or Methionine Sulfoximine (MSX). Stably transfected CHO-DG44 cells producing highest levels of the selected chimeric mouse-human MAbs with the best neutralizing activities against BP and BM have been established by using two bicistronic vectors with amplification markers. The humanized MAbs produced were successfully purified and re-analyzed for their binding affinity and neutralizing activity against BP and BM. Selection of MAbs for further improvement of antigen binding affinity was based on in vitro bacterial killing and in vivo animal protection assays. To construct antibody expression vector, we used the mammalian expression plasmid pIRES which contains two Multiple Cloning Sites (MCS-A and MCS-B) and allows expression of two genes at high level simultaneously. We modified pIRES by inserting the DHFR gene separately at the MCS-B (pIRES-DHFR). The genes of chimeric heavy or light chains was introduced into MCS-A on separate plasmid of the pIRES-DHFR vector. In brief, overlapping PCR technique was used to assemble full fragments of heavy or light chain genes containing Kozak sequences, synthetic leader heavy (light) sequences and human constant gamma 1 (kappa) sequences and restriction sites. These two constructed vectors (pIRES-H-DHFR and pIRES-L-DHFR) was cotransfected into CHODG44 cells by lipofectamine 2000 reagent and amplified in culture medium containing stepwise increments of MTX (Kim et al., 2011b). DHFR amplification is based on systematic increases of MTX in medium without added nucleosides. Cells are qualified for next amplification step after regaining their polygonal morphology (2-3 weeks). Since the concentration of MTX is expected to increase about $16,000 \times$ (from $0.005 \mu \mathrm{M}$ to about $80 \mu \mathrm{M}$ ) the amplification process will take about 4 months taking into consideration that 4 times increase in MTX is applied in each amplification step (Kim et al., 1998). At certain time points of MTX amplification, single clones are separated and tested for expression level and binding affinity by ELISA.

We established a platform technology for fastperformance production of stable chimeric MAbs against BP and/or BM by CHO-DG44 cells using the effective expression vector systems (Kim et al., 2011b). Overall, we have generated 6 mammalian expression vectors, incorporating an Internal Ribosome Entry Site
(IRES) and Foot and Mouse Disease Virus (FMDV)derived $2 \mathrm{~A}$ self-processing sequence that efficiently mediated the (co)expression of two transgenes in multiple mammalian cell types. These 6 vectors would be useful for various cMAb productions in the laboratory but also genetic immunotherapy strategies where more than one gene product is needed to mount an effective immune response. The utilization of either bicistronic pIRES-H(L)-DHFR or p2A-H(L)-DHFR vectors has been shown as the most effective method in obtaining stable cell lines that express high levels of the cMAbs (Kim et al., 2011b). Therefore, two systems utilizing single gene vectors might be more relevant than other systems for maintaining intact binding properties after chimerization and higher level production of chimeric MAbs by mammalian host cells.

Recent progresses in antibody engineering, cell transfection technology and expression systems containing selective markers allow highly efficient transfection of mammalian cells for the fast production of therapeutic MAbs (Chowdhury and $\mathrm{Wu}, 2005$; Reichert, 2011; Wurm, 2004). The efficient transfection of cells not only facilitates stable cell clone generation, but also allows true preclinical development of cMAb production in transiently transfected cells for smallscale production. Using the DHFR double deletion mutant (dhfr/dhfr') CHO-DG44 cells, we were able to amplify the chimeric antibody gene associated with the amplifiable DHFR gene by systematic increases of MTX in medium without added nucleosides. For preclinical development of therapeutic chimeric MAbs, it is critical to obtain a thoroughly guaranteed stable clone derived from a single clone producing stable cMAbs. Using the bicistronic pIRES-H (L)-DHFR vector system, approximately six months was usually required due to selection/amplification and adaptation to serum-free conditions. By using cloning cylinders and applying a less toxic Lipofectamine (LF-LTX) reagent to the highly confluent CHO-DG44 cells ( 90\%), we significantly reduced the time and increased the probability of finding the positive clone. Although tedious time is still required for these procedures, the end-results obtained through the selection/amplification processes allow us to use chimeric MAbs resembling the original human MAbs for all kinds of clinical applications, potentially leading to better results in therapeutic development against Burkholderia infection.

Considering the production levels and binding properties of chimeric MAbs produced by transient transfection using 8 different mammalian host cells, the cell lines (CHO-K1, COS-7, 293T and BHK-21) were more productive than other mammalian cells tested (Kim et al., 2011b). However, for large-scale 
production, the CHO-DG44 cells are only available in obtaining stable clones due to the property of deficient DHFR genes within host chromosomes. Thus, we can continuously amplify the target antibody gene up to certain MTX levels without causing any cell damage. When producing therapeutic MAb, the CHO-DG44 cell line makes an ideal cell factory since their therapeutic MAbs largely correspond to genuine human MAbs with similar patterns of post-translational modification and glycosylation (Wurm, 2004). The availability of commercial media of high quality for cell culture is an additional factor that would support large-scale production of cMAbs in this cell line.

\section{Efficient expression of 3 lead chimeric MAbs against} BP and BM: A new development of antibody engineering technology not only facilitates a simpler approach for the generation of stable cell clones, it also turns more humanized MAb production in mammalian cells (Adams and Weiner, 2005; Dubel, 2007; Thie et al., 2008). This allows us to use certain amounts of MAbs resembling the original human MAb for human applications, potentially leading to better results in clinical trial and therapeutic development. The demand for therapeutic MAbs is increasing. More and more MAbs are required for research applications and numerous new MAb-based therapeutics are in preclinical or clinical testing, constituting an increasing need for new clinical-grade expression systems and large-scale production capabilities (Thie et al., 2008; Weiner et al., 2010). The major reason for choosing mammalian expression system is due to the posttranslational modifications of the therapeutic MAbs largely correspond to the genuine human patterns and that correspondence is indispensable when it comes to mediating immune effector functions. Since the engineered MAb production rates in mammalian cells are relatively low, many different efforts have been made to improve those rates. The efforts have been focused on improvements of expression vectors, antibody gene transfection, medium development, highthroughput screening methods and downstream process for purification of end product MAbs. However, although these improvements have given to a leading role to mammalian cells in the large scale production of therapeutic MAbs, little improvement has been made with respect to small-scale $\mathrm{MAb}$ production in mammalian cells.

The most frequently used cell lines tor MAb production are $\mathrm{CHO}$ cells, Baby Hamster Kidney (BHK-21), transformed African green monkey kidney Cells (COS-7), mouse myeloma (NSO), transformed human embryonic kidney with $\mathrm{T}$ antigen (293T).
Commercial media of high quality are available for cell culture. When it comes to therapeutic MAb production, however, cell culture processes are executed in serumfree media to reduce cost of downstream processes. Modern media compositions support excellent cell culture performance in the absence of serum provided peptides, growth factors and an undetermined collection of proteins, lipids, carbohydrates and small molecules. Efficient gene transfer into mammalian cells relevant for MAb production purposes has been a major challenge. Viral vector systems usually have the advantage of high transfection efficiencies compared to non-viral methods. However, these methods suffer from several limitations such as the time-consuming and laborious construction of vectors, elevated laboratory costs due to the high level of safety requirements, limitation of insert size and possible immunogenic reaction in clinical trials (Thomas et al., 2003). Nonviral gene transfer methods include calcium phosphate, lipofectamine reagents, electroporation and ballistic gene transfer (Nildome and Huang, 2002). Whereas electroporation and ballistic techniques usually lead to high cell mortality, calcium phosphate and lipofectamine often result in low transfection efficiencies especially in suspension cells. The electroporation-based transfection technology is a valid alternative and has been proven to be efficient even in suspension cells relevant for MAb production.

\section{CONCLUSION}

BP and BM, the causative agents of melioidosis and glanders, respectively, are priority pathogens which have increased the interest of the scientific community as category B select agents. They are highly virulent pathogens that might have been developed as bioweapons. There are no effective vaccines available to either of these 2 pathogens. During the past 5 years we have successfully developed high-performance therapeutic MAbs against BP and BM [from mouse MAbs to chimeric MAbs or fully human MAbs] to prevent melioidosis and glanders diseases of humans and animals. Throughout the conventional hybridoma technique, total 108 MAbs against BP and BM were generated and characterized (Zou et al., 2008). Six lead MAbs were evaluated using BALB/c mice challenged intranasally with a lethal dose of the bacteria (Zhang et al., 2011). Some of MAbs have been developed into chimeric MAbs, or fully human MAbs through antibody engineering [variable gene cloning, mammalian expression and mouse (or human) $\mathrm{scFv}$ antibody library techniques]. Overall, we generated 10 chimeric MAbs (3 stable MAbs and 7 transient MAbs) and one fully human MAb against BP and BM (Table 
2). Other techniques [transgenic mouse, Epstein-Barr virus (EBv)-hybridoma and CDR-graft] (Fig. 1 and 2) are also promising to make efficient human(ized) MAbs, although these 3 approaches were not tried in our laboratory. Furthermore, a platform technology for ideal therapeutic MAbs against BP and BM (construction of expression vector systems and optimization of transfection/selection for stable production) has been established (Kim et al., 2011b).

\section{ACKNOWLEDGMENT}

This research was supported by grants 2.10014_05_AF_B and 2.1_07_AF_B from the Defense Threat Reduction Agency-Joint Science and Technology Office. We thank Drs. Shaw-Huey Feng and Shien Tsai for their contribution in generating mouse MAbs. We also thank Tommy Kim for editorial assistance.

\section{REFERENCES}

Adams, G.P. and L.M. Weiner, 2005. Monoclonal antibody therapy of cancer. Nat. Biotechnol., 23: 1147-1157. DOI: $10.1038 / n b t 1137$

Altschul, S.F., T.L. Madden, A.A. Schaffer, J. Zhang and Z. Zhang et al., 1997. Gapped BLAST and PSI-BLAST: A new generation of protein database search programs. Nucl. Acids Res., 25: 3389-3402. DOI: $10.1093 /$ nar/25.17.3389

Anuntagool, N. and S. Sirisinha, 2002. Antigenic relatedness between Burkholderia pseudomallei and Burkholderia mallei. Microbiol. Immunol., 46: 143-150. PMID: 12008922

Bianchi, A.A. and J.T. McGrew, 2003. High-level expression of full-length antibodies using transcomplementing expression vectors. Biotechnol. Bioeng., 84: 439-444. DOI: 10.1002/bit.10790

Bondi, S.K. and J.B. Goldberg, 2008. Strategies toward vaccines against Burkholderia mallei and Burkholderia pseudomallei. Expert Rev. Vaccines, 7: 1357-1365. DOI: 10.1586/14760584.7.9.1357

Brekke, O.H. and I. Sandlie, 2003. Therapeutic antibodies for human diseases at the dawn of the twenty-first century. Nat. Rev. Drug. Discov., 2: 52-62. PMID: 12509759

Canziani, G.A., S. Klakamp and D.G. Myszka, 2004. Kinetic screening of antibodies from crude hybridoma samples using Biacore. Anal. Biochem., 325: 301-307. DOI: 10.1016/j.ab.2003.11.004
Casadevall, A., 2002. Passive antibody administration (immediate immunity) as a specific defense against biological weapons. Emerg. Infect. Dis., 8: 833841. PMID: 12141970

Chan, S.W., G.I. Ong and S. Nathan, 2004. Neutralizing chimeric mouse-human antibodies against Burkholderia pseudomallei protease: Expression, purification and characterization. Biochem. Mol. Biol., 37: 556-564. PMID: 15479619

Chaowagul, W., N.J. White, D.A.B. Dance, Y. Wattanagoon and P. Naigowit et al., 1989. Melioidosis: A major cause of community-acquired septicemia in northeastern Thailand. J. Infect. Dis., 159: 890-899. DOI: 10.1093/infdis/159.5.890

Chaowagul, W., Y. Suputtamongkol, D.A. Dance, A. Rajchanuvong and J. Pattara et al., 1993. Relapse in melioidosis: incidence and risk factors. J. Infect. Dis., $\quad 168$ : 1181-1185. DOI: 10.1093/infdis/168.5.1181

Cheng, A.C. and B.J. Currie, 2005. Melioidosis: epidemiology, pathophysiology and management. Clin. Microbiol. Rev., 18: 383-416. DOI: 10.1128/CMR.18.2.383-416.2005

Chowdhury, P.S. and H. Wu, 2005. Tailor-made antibody therapeutics. Methods, 36: 11-24. DOI: 10.1016/j.ymeth.2005.01.002

Cravitz, L. and W.R. Miller, 1950. Immunologic studies with Malleomyces Mallei and Malleomyces Pseudomallei. I. Serological relationships between M. mallei and M. pseudomallei. J. Infect. Dis., 86: 46-51. DOI: 10.1093/infdis/86.1.46

Currie, B.J., D.A. Dance and A.C. Cheng, 2008. The global distribution of Burkholderia pseudomallei and melioidosis: An update. Trans. R. Soc. Trop. Med. Hyg., 102: S1-S4. PMID: 19121666

Dubel, S., 2007. Recombinant therapeutic antibodies. Applied Microbiol. Biotechnol., 74: 723-729. DOI: 10.1007/s00253-006-0810-y

Estes, D.M., S.W. Dow, H.P. Schweizer and A.G. Torres, 2010. Present and future therapeutic strategies for melioidosis and glanders. Expert Rev. Anti. Infect. Ther., 8: 325-338. DOI: 10.1586/eri.10.4

Felgner, P.L., M.A. Kayala, A. Vigil, C. Burk and R. Nakajima et al., 2009. A Burkholderia pseudomallei protein microarray reveals serodiagnostic and cross-reactive antigens. Proc. Natl. Acad. Sci., 106: 13499-13504. PMID: 19666533 
Feng, S.H., S. Tsai, J. Rodriguez, T. Newsome and P. Emanuel et al., 2006. Development of mouse hybridomas for production of monoclonal antibodies specific to Burkholderia mallei and Burkholderia pseudomallei. Hybridoma, 25: 193201. DOI: 10.1089/hyb.2006.25.193

Fishwild, D.M., S.L. O'Donnell, T. Bengoechea, D.V. Hudson and F. Harding et al., 1996. High-avidity human IgGK monoclonal antibodies from a novel strain of minilocus transgenic mice. Nat. Biotechnol., 14: 845-851. PMID: 9631008

Fong, I.W. and K. Alibek, 2005. Bioterrorism and Infectious Agents: A New Dilemma for the 21st Century. 1st Edn., Springer, USA., ISBN-10: 0387236848, pp: 273.

Gao, C., S. Mao, G. Kaufmann, P. Wirsching and R.A. Lerner et al., 2002. A method for the generation of combinatorial antibody libraries using pIX phage display. Proc. Natl. Acad. Sci., 99: 12612-126126. DOI: 10.1073/pnas.192467999

Groot, A.S.D. and R. Rappuoli, 2004. Genome-derived vaccines. Expert Rev. Vaccines, 3: 59-76. DOI: 10.1586/14760584.3.1.59

Hara, Y., R. Mohamed and S. Nathan, 2009. Immunogenic Burkholderia pseudomallei outer membrane proteins as potential candidate vaccine targets. PLoS ONE, 4: e6496-e6496. DOI: 10.1371/journal.pone.0006496

Howe, C., A. Sampath and M. Spotnitz, 1971. The pseudomallei group: A review. J. Infect. Dis., 124: 598-606. DOI: 10.1093/infdis/124.6.598

Huls, G.A., I.A.F.M. Heijnen, M.E. Cuomo, J.C. Koningsberger and L. Wiegman et al., 1999. A recombinant, fully human monoclonal antibody with antitumor activity constructed from phagedisplayed antibody fragments. Nat. Biotechnol., 17: 276-281. DOI: 10.1038/7023

Ip, M., L.G. Osterberg, P.Y. Chau and T.A. Raffin, 1995. Pulmonary melioidosis. CHEST, 108: 14201424. DOI: $10.1378 /$ chest.108.5.1420

Irving, R.A., A.A. Kortt and P.J. Hudson, 1996. Affinity maturation of recombinant antibodies using E. coli mutator cells. Immunotechnology, 2: 127-143. DOI: 10.1016/1380-2933(96)00044-9

Jakobovits, A., 1995. Production of fully human antibodies by transgenic mice. Curr. Opin. Biotechnol., 6: 561-566. PMID: 7579668

Jones, A.L., T.J. Beveridge and D.E. Woods, 1996. Intracellular survival of Burkholderia pseudomallei. Infect. Immun., 64: 782-790. PMID: 8641782
Jones, S.M., J.F. Ellis, P. Russel, K.F. Griffin and P.C. Oyston, 2002. Passive protection against Burkholderia pseudomallei infection in mice by monoclonal antibodies against capsular polysaccharide, lipopolysaccharide or proteins. J. Med. Microbiol., 51: 1055-1062. PMID: 12466403

Jun, S.C., M.S. Kim, H.J Hong and G.M. Lee, 2006. Limitations to the development of humanized antibody producing Chinese hamster ovary cells using glutamine synthetase-mediated gene amplification. Biotechnol. Prog., 22: 770-780. DOI: $10.1021 / \mathrm{bp} 060004 \mathrm{t}$

Karpas, A., A. Dremucheva and B.H. Czepulkowski, 2001. A human myeloma cell line suitable for the generation of human monoclonal antibodies. Proc. Natl. Acad. Sci., 98: 1799-1804. DOI: 10.1073/pnas.98.4.1799

Kim, S.J., N.S. Kim, C.J. Ryu, H.J. Hong and G.M. Lee, 1998. Characterization of chimeric antibody producing $\mathrm{CHO}$ cells in the course of dihydrofolate reductase-mediated gene amplification and their stability in the absence of selective pressure. Biotechnol. Bioeng., 58: 73-84. DOI: 10.1002/(SICI)10970290(19980405)58:1<73::AID-BIT8>3.0.CO;2-R

Kim, H.S., S.C. Lo, D.J. Wear, A. Stojadinovic and P.J. Weina et al., 2011a. Improvement of antiBurkholderia mouse monoclonal antibody from various phage-displayed single-chain antibody libraries. J. Immunol. Methods, 372: 146-161. DOI: 10.1016/j.jim.2011.07.009

Kim, H.Y., S. Tsai, S.C Lo, D.J. Wear and M.J. Izadjoo, 2011b. Production and characterization of chimeric monoclonal antibodies against Burkholderia pseudomallei and B. mallei using the DHFR expression system. PLoS ONE, 6: e19867e19867. DOI: 10.1371/journal.pone.0019867

Kohler, G. and C. Milstein, 1975. Continuous cultures of fused cells secreting antibody of predefined specificity. Nature, 256: 495-497. PMID: 1172191

Koponen, M.A., D. Zlock, D.L. Palmer and T.L. Merlin, 1991. Melioidosis. Forgotten, but not gone. Arch. Intern. Med., 151: 605-608. PMID: 2001144

Kuroiwa, Y., P. Kasinathan, T. Sathiyaseelan, J.A. Jiao and H. Matsushita et al., 2009. Antigen-specific human polyclonal antibodies from hyperimmunized cattle. Nat. Biotechnol., 27: 173181. DOI: $10.1038 /$ nbt. 1521

Leelarasamee, A. and S. Bovornkitti, 1989. Melioidosis: review and update. Rev. Infect. Dis., 11: 413-425. PMID: 2665001

Leelarasamee, A., 2004. Recent development in melioidosis. Curr. Opin. Infect. Dis., 17: 131-136. PMID: 15021053 
Li, J., T. Sai, M. Berger, Q. Chao and D. Davidson et al., 2006. Human antibodies for immunotherapy development generated via a human B cell hybridoma technology. Proc. Natl. Acad. Sci., 103: 3557-3562. DOI: 10.1073/pnas.0511285103

Lonberg, N. and D. Huszar, 1995. Human antibodies from transgenic mice. Int. Rev. Immunol., 13: 6593. PMID: 7494109

Lonberg, N., 2005. Human antibodies from transgenic animals. Nat. Biotechnol., 23: 1117-1125. DOI: $10.1038 /$ nbt1135

Lonberg, N., 2008. Fully human antibodies from transgenic mouse and phage display platforms. Curr. Opin. Immunol., 20: 450-459. DOI: 10.1016/j.coi.2008.06.004

Low, N.M., P. Holliger and G. Winter, 1996. Mimicking somatic hypermutation: Affinity maturation of antibodies displayed on bacteriophage using a bacterial mutator strain. J. Mol. Biol., 260: 359-368. DOI: 10.1006/jmbi.1996.0406

Lucas, B.K., L.M. Giere, R.A. DeMarco, A. Shen and V. Chisholm et al., 1996. High-level production of recombinant proteins in $\mathrm{CHO}$ cells using a dicistronic DHFR intron expression vector. Nucl. Acids Res., 24: 1774-1779. DOI: 10.1093/nar/24.9.1774

Mukhopadhya, A., V. Balaji, M.V. Jesudason, A. Amte and R. Jeyamani et al., 2007. Isolated liver abscesses in melioidosis. Indian J. Med. Microbiol., 25: 150-151. PMID: 17582188

Nelson, M., J.L. Prior, M.S. Lever, H.E. Jones and T.P. Atkins et al., 2004. Evaluation of lipopolysaccharide and capsular polysaccharide as subunit vaccines against experimental melioidosis. J. Med. Microbiol., 53: 1177-1182. DOI: 10.1099/jmm.0.45766-0

Neuberger, M.S. and C. Milstein, 1995. Somatic hypermutation. Curr. Opin. Immunol, 7: 248-254. DOI: 10.1016/0952-7915(95)80010-7

Nildome, T. and L. Huang, 2002. Gene therapy progress and prospects: Nonviral vectors. Gene Therapy, 9: 1647-1652. DOI: 10.1038/sj.gt.3301923

Plesa, M., A. Kholti, K. Vermis, P. Vandamme and S. Panagea et al., 2004. Conservation of the opcL gene encoding the peptidoglycan-associated outermembrane lipoprotein among representatives of the Burkholderia cepacia complex. J. Med. Microbiol., 53: 389-398. DOI: 10.1099/jmm.0.05504-0
Reckseidler, S.L., D. DeShazer, P.A. Sokol and D.E. Woods, 2001. Detection of bacterial virulence genes by subtractive hybridization: Identification of capsular polysaccharide of Burkholderia pseudomallei as a major virulence determinant. Infect. Immun., 69: 34-44. DOI: 10.1128/IAI.69.1.34-44.2001

Reff, M.E., K. Carner, K.S. Chambers, P.C. Chinn and J.E. Leonard et al., 1994. Depletion of B cells in vivo by a chimeric mouse human monoclonal antibody to CD20. Blood, 83: 435-445. PMID: 7506951

Reichert, J.M., 2002. Therapeutic monoclonal antibodies: Trends in development and approval in the US. Curr. Opin. Mol. Ther., 4: 110-118. PMID: 12044031

Reichert, J.M., 2011. Antibody-based therapeutics to watch in 2011. MAbs, 3: 76-99. PMID: 21051951

Rogul, M., J.J. Brendle, D.K. Haapala and A.D. Alexander, 1970. Nucleic acid similarities among Pseudomonas pseudomallei, Pseudomonas multivorans and Actinobacillus mallei. J. Bacteriol., 101: 827-835. PMID: 5438051

Thie, H., T. Meyer, T. Schirrmann, M. Hust and S. Dubel, 2008. Phage display derived therapeutic antibodies. Curr. Pharm. Biotechnol., 9: 439-446. PMID: 19075684

Thie, H., L. Toleikis, J. Li, R.V. Wasielewski and G. Bastert et al., 2011. Rise and Fall of an AntiMUC1 specific antibody. PLoS ONE, 6: e15921e15921. DOI: 10.1371/journal.pone.0015921

Thomas, C.E., A. Ehrhardt and M.A. Kay, 2003. Progress and problems with the use of viral vectors for gene therapy. Nat. Rev. Genetics, 4: 346-358. DOI: $10.1038 / \mathrm{nrg} 1066$

Traggiai, E., S. Becker, K. Subbarao, L. Kolesnikova and Y. Uematsu et al., 2004. An efficient method to make human monoclonal antibodies from memory B cells: potent neutralization of SARS coronavirus. Nat. Med., 10: 871-875. DOI: 10.1038/nm1080

Trevino, S.R., A.R. Permenter, M.J. England, N. Parthasarathy and P.H. Gibbs et al., 2006. Monoclonal antibodies passively protect BALB/c mice against Burkholderia mallei aerosol challenge. Infect. Immun., 74: 1958-1961. DOI: 10.1128/IAI.74.3.1958-1961.2006

Vaisbourd, M., O. Ignatovich, A. Dremucheva, A. Karpas and G. Winter, 2001. Molecular characterization of human monoclonal antibodies derived from fusions of tonsil lymphocytes with a human myeloma cell line. Hybrid. Hybridomics, 20: $287-292$. DOI: $10.1089 / 15368590152740680$ 
Vaswani, S.K. and R.G. Hamilton, 1998. Humanized antibodies as potential therapeutic drugs. Ann. Allergy Asthma Immunol., 81: 105-115. PMID: 9723555

Vaughan, T.J., J.K. Osbourn and P.R. Tempest, 1998. Human antibodies by design. Nat. Biotechnol., 16: 535-539. DOI: 10.1038/nbt0698-535

Wark, K.L. and P.J. Hudson, 2006. Latest technologies for the enhancement of antibody affinity. Adv. Drug Delivery Rev., 58: 657-670. DOI: 10.1016/j.addr.2006.01.025

Weiner, L.M., R. Surana and S. Wang, 2010. Monoclonal antibodies: Versatile platforms for cancer immunotherapy. Nat. Rev. Immunol., 10: 317-327. DOI: 10.1038/nri2744

White, N.J., 2003. Melioidosis. Lancet, 361: 17151722. DOI: 10.1016/S0140-6736(03)13374-0

Whitlock, G.C., D.M. Estes and A.G. Torres, 2007. Glanders: Off to the races with Burkholderia mallei. FEMS Microbiol. Lett., 277: 115-122. DOI: 10.1111/j.1574-6968.2007.00949.x

Wiersinga, W.J., T.V.D. Poll, N.J. White, N.P. Day and S.J. Peacock, 2006. Melioidosis: Insights into the pathogenicity of Burkholderia pseudomallei. Nat. Rev. Microbiol., 4: 272-282. DOI: 10.1038/nrmicro1385

Wohlhueter, R.M., K. Parekh, V. Udhayakumar, S. Fang and A.A. Lal, 1994. Analysis of binding of monoclonal antibody to a malarial peptide by surface plasmon resonance biosensor and integrated rate equations. J. Immunol., 153: 181189. PMID: 8207235
Wurm, F.M., 2004. Production of recombinant protein therapeutics in cultivated mammalian cells. Nat. Biotechnol., 22: 1393-1398. DOI: 10.1038/nbt1026

Yau, K.Y.F., G. Dubuc, S. Li, T. Hirama and C.R. MacKenzie et al., 2005. Affinity maturation of a $\mathrm{V}_{\mathrm{H}} \mathrm{H}$ by mutational hotspot randomization. $\mathrm{J}$. Immunol. Methods, 297: 213-224. DOI: 10.1016/j.jim.2004.12.005

Zhang, H., D.W. Niesel, J.W. Peterson and G.R. Klipel, 1998. Lipoprotein release by bacteria: Potential factor in bacterial pathogenesis. Infect. Immun., 66: 5196-5201. PMID: 9784522

Zhang, S., S.H. Feng, B. Li, H.Y. Kim and J. Rodriguez et al., 2011. In vitro and In vivo studies of monoclonal antibodies with prominent bactericidal activity against Burkholderia pseudomallei and Burkholderia mallei. Clin. Vaccine Immunol., 18: 825-834. DOI: $10.1128 / C V I .00533-10$

Zou, N., T. Newsome, B. Li, S. Tsai and S.C. Lo, 2007. Human single-chain Fv antibodies against Burkholderia mallei and Burkholderia pseudomallei. Exp. Biol. Med. (Maywood), 232: 550-556. PMID: 17392491

Zou, N., S. Tsai, S.H. Feng, T. Newsome and H.Y. Kim et al., 2008. Relationship between antigenicity and pathogenicity for Burkholderia pseudomallei and Burkholderia mallei revealed by a large panel of mouse MAbs. Hybridoma, 27: 231-240. DOI: 10.1089/hyb.2008.0012 